\title{
Necrotic ulcerated and bleeding striae distensae following bevacizumab in a palliative setting for gliobastomatosis cerebri
}

\author{
Olivia Laugier ${ }^{1}$, Laetitia Padovani ${ }^{2,3}$, Arnauld Verschuur ${ }^{1}$, Caroline Gaudy-Marqueste ${ }^{4}$ and Nicolas André1,3,5 \\ 1Department of Pediatric Hematology and Oncology, AP-HM, Boulevard Jean Moulin, 13005, Marseille France \\ ${ }^{2}$ Department of Radiotherapy, AP-HM, Aix-Marseille Université, Boulevard Jean Moulin, 13005, Marseille, France \\ IInserm UMR_S 911, Centre de Recherche en Oncologie biologique et Oncopharmacologie, Aix-Marseille Université, Boulevard Jean Moulin, 13005, \\ Marseille, France \\ ${ }^{4}$ Department of Dermatology, AP-HM, Boulevard Jean Moulin, 13005, Marseille, France \\ ${ }^{5}$ OncoSafetyNetwork, AP-HM, Boulevard Jean Moulin, 13005, Marseille, France
}

Correspondence to: Nicolas André. Email: Nicolas.andre@ap-hm.fr

\begin{abstract}
Glioblastoma cerebri is a rare paediatric malignancy with dismal prognosis [Chappé C, Riffaud L, and Tréguier C et al (2013) Primary gliomatosis cerebri involving gray matter in pediatrics: a distinct entity? A multicenter study of $\mathbf{1 4}$ cases Childs Nerv Syst 29 565-571 https://doi.org/10.1007/s00381-012-2016-1 PMID: 23306961] and no established standard of care. Here, we report a case of ulcerated and bleeding striae distensae in a teenage girl following palliative treatment with bevacizumab and steroids.
\end{abstract}

Keywords: glioblastoma, bevacizumab, steroids, palliative care, skin lesions

Published: 07/08/2017

Received: 26/03/2017

ecancer 2017, 11:756 https://doi.org/10.3332/ecancer.2017.756

Copyright: (c) the authors; licensee ecancermedicalscience. This is an Open Access article distributed under the terms of the Creative Commons Attribution License (http://creativecommons.org/licenses/by/3.0), which permits unrestricted use, distribution, and reproduction in any medium, provided the original work is properly cited. 


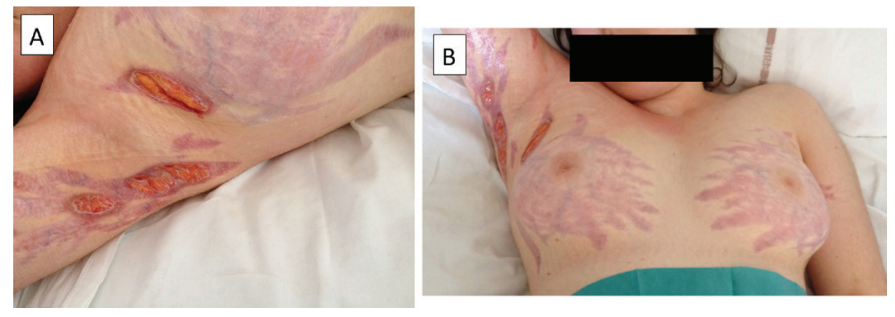

Figure 1. Ulceration of diffuse corticosteroid-induced striae in a teenage patient on bevacizumab for the treatment of advanced glioblastomatosis cerebri.

A 15-year-old girl, without previous medical history was referred to our department for investigation in August 2013. Magnetic resonance imaging revealed an infiltrative mass involving both thalami and the temporal lobe. A surgical biopsy was performed and pathological analysis confirmed a diagnosis of WHO grade-IV glioblastoma, so that together with the radiological extent the diagnosis of gliomatosis cerebri was made. The K28M mutation in the histone H3.3 gene (H3F3A) was found. No mutation in IDH1, IDH2, or Braf were found.

No surgical resection was initiated because of both the large size of the tumour and its location. She was initially treated with metronomic temozolomide $\left(50 \mathrm{mg} / \mathrm{m}^{2} / \mathrm{day}\right.$ ) in combination with radiotherapy (54 Gy) with subsequent monthly courses of temozolomide $200 \mathrm{mg} / \mathrm{m}^{2}$ for 5 days every 4 weeks [2]. Valproic acid as a histone deacetylase (HDAC) inhibitor was added (30 mg/kg/day) to the combination [3]. Clinical and radiological progression were observed 7 months after the end of radiotherapy. A metronomic therapy [4] with oral weekly vinorelbine, daily celecoxib and daily valproic acid was then started and lasted until February 2015 (13 months), when new tumour progression was observed.

She then underwent re-irradiation, followed by bevacizumab (10 mg/kg every 2 weeks) and steroids (prednisolone $1 \mathrm{mg} / \mathrm{kg}$ ) as a palliative approach. After three injections of bevacizumab, bilateral striae distensae developed on the breasts, inguinal, and axillary areas. Despite bevacizumab discontinuation, the skin lesions rapidly became necrotic and ulcerated and very painful (Figure 1). Management of the skin lesions required prolonged hospitalisation for wound dressing and pain management with morphine administration. The patient died of progressive disease with unhealed striae distensae.

\section{Discussion}

The role of bevacizumab in the treatment of glioblastoma in adults remains controversial [5], although it is frequently used at relapse to try to increase survival. In children with high-grade glioma, bevacizumab does not seem to display efficacy [6] and its role in first-line treatment have been evaluated in the randomised Herby trial [7].

In children with brain tumours treated with bevacizumab toxicities are known, and the risk of defects in wound healing well identified [6], but the occurrence of multiple ulcerated striae distensae is a very rare event [8]. In adults, similar findings have also been reported [9-14] and such cutaneous toxicities very likely result from the combination of steroids and bevacizumab. Patients with a primary brain tumour not uncommonly require chronic corticosteroid therapy and consequently can suffer from striae distensae. The addition of bevacizumab which is known to hamper wound healing [10] likely contributed to the prolonged delayed in wound healing in the patient we report here.

\section{Conclusion}

This case highlights the importance of weighing any benefits with the potential risks associated with palliative anticancer treatment, especially when using new agents outside of clinical trials. Indeed, even if their toxicity profile seems favourable, physicians should be aware of limited knowledge about their toxicity, especially in children. In the case, we report here, in retrospect the side effects associated with the use of bevacizumab ultimately may have outweighed the potential benefits, with significant pain and a prolonged hospital stay. This may justify limiting its use as a palliative approach in children with high-grade glioma. 


\section{References}

1. Chappé C, Riffaud L, and Tréguier C et al (2013) Primary gliomatosis cerebri involving gray matter in pediatrics: a distinct entity? A multicenter study of 14 cases Childs Nerv Syst 29 565-571 https://doi.org/10.1007/s00381-012-2016-1 PMID: 23306961

2. Stupp R, Mason WP, and van den Bent MJ et al (2005) Radiotherapy plus concomitant and adjuvant temozolomide for glioblastoma N Engl J Med 352 987-996 https://doi.org/10.1056/NEJMoa043330 PMID: 15758009

3. Su, JM, Li XN, and Thompson $\mathrm{P}$ et al (2011) Phase 1 study of valproic acid in pedaitric patietns with refractory solid or CNS tumors: a Children's Oncology Group report Clin Cancer Res 17 589-597 https://doi.org/10.1158/1078-0432.CCR-10-0738

4. André N, Carré M, Pasquier E (2014) Metronomics: towards personalized chemotherapy? Nat Rev Clin Oncol 11 413-431 https://doi.org/10.1038/nrclinonc.2014.89 PMID: 24913374

5. Fu P, He YS, and Huang Q, et al (2016) Bevacizumab treatment for newly diagnosed glioblastoma: systematic review and meta-analysis of clinical trials Mol Clin Oncol 4 833-838 PMID: 27123291 PMCID: 4840497

6. Gururangan S, Chi SN, Poussaint TY (2010) Lack of efficacy of bevacizumab plus irinotecan in children with recurrent malignant glioma and diffuse brainstem glioma: a Pediatric Brain Tumor Consortium Study J Clin Oncol 28 3069-3075 https://doi. org/10.1200/JCO.2009.26.8789 PMID: 20479404 PMCID: 2903337

7. Grill J, Hargrave D, and Massimino M et al (2016) A Phase II open label, randomized, multicenter comparative study of bevacizumab based therapy in paediatric patients with newly diagnosed supratentorial, infratentorial cerebellar, or pedoncular high grade glioma Neuro Oncol 18(Suppl 3) iii 77 PMCID: 4903389

8. Couec ML, André N, and Thebaud E, et al (2012) Bevacizumab and irinotecan in children with recurrent or refractory brain tumors: toxicity and efficacy trends Pediatr Blood Cancer 59 34-38 https://doi.org/10.1002/pbc.24066 PMID: 22287258

9. Wheeler H, Black J, and Webb S, et al (2012) Dehiscence of corticosteroid-induced abdominal striae in a 14-year-old boy treated with bevacizumab for recurrent glioblastoma J Child Neurol 27 927-929 https://doi.org/10.1177/0883073811428007

10. Ladha H, Pawar T, and Gilbert MR, et al (2015) Wound healing complications in brain tumor patients on bevacizumab J Neurooncol 124 501-506 https://doi.org/10.1007/s11060-015-1868-0 PMID: 26298437

11. Farber SA, Samimi S, and Rosenbach M (2015) Ulcerations within striae distensae associated with bevacizumab therapy $J$ Am Acad Dermatol 72 e33-e35 https://doi.org/10.1016/j.jaad.2014.09.023

12. Dosal J, Handler MZ (2012) Ulceration of abdominal striae distensae (stretch marks) in a cancer patient Arch Dermatol 148 385-390 https://doi.org/10.1001/archderm.148.3.385-c PMID: 22431783

13. Fourcade S, Gaudy-Marqueste C, and Tasei AM, et al (2011) Localized skin necrosis of steroid-induced striae distensae: an unusual complication of bevacizumab and irinotecan therapy Arch Dermato/ 147 1227-1228 https://doi.org/10.1001/archdermatol.2011.311 PMID: 22006149

14. Peters KB, Coyle TE, and Vredenburgh JJ, et al (2011) Ulceration of striae distensae in high-grade glioma patients on concurrent systemic corticosteroid and bevacizumab therapy J Neurooncol 101 155-159 https://doi.org/10.1007/s11060-010-0239-0 